\title{
A Comparative Study of Two Chinese Bible Versions-the CUV and the TCV
}

\author{
Gong Yichao \\ Foreign Language College \\ Hainan Normal University \\ Haikou, China \\ gycerica@aliyun.com
}

\begin{abstract}
The thesis aims to find out the differences between the two Chinese versions of Bible, namely the Chinese Union Version and Today's Chinese Version in aspects like translation principles, language, treatment of theological terms and metaphors, etc. Based on the comparative study, the author provides suggestions for improvements of the two versions and future translations.
\end{abstract}

Keywords-Chinese Bible translation; comparative study; the Chinese Union Version; the Today's Chinese Version

\section{INTRODUCTION}

The Bible is not only an important part of the Western culture, but also has significant influence on Chinese culture through the thousand-year history of Chinese Bible translation. Though various versions were produced during this long history, for most people, Christians and non-Christians alike, the Chinese Bible equals the Chinese Union Version (the CUV). However, the principles and methodologies which guided the translation process of it are new to many people. Today's Chinese Version (the TCV) published in the 1970s, on the other hand, did not arouse much attention of Chinese readers, though its translators had claimed to have produced a version for non-Christians which made up the majority of Chinese population.

The thesis aims to find out the differences between the two versions. Part I explores the principles which guided the translating processes of the two versions. In Part II, the author conducts a comparative analysis of the New Testament texts of the two versions in language, treatments of theological terms, metaphors and gender, etc. Through the comparative study, the features of the two versions are made clear.

\section{THE CUV AND THE TCV---PRINCIPLES}

\section{A. The Principles in the Translation of the CUV}

In a conference held in Shanghai in 1890, it was decided that all union versions would use the Revised Version of King James Version (RV) published in 1885 as the textual basis.

In a meeting in 1891, the translation committee set up 4 translation principles:

First, the target language should be the widely used language throughout the country, not dialects limited to a region.
Second, the target language should be featured with simplicity and clarity, which, when read aloud in the church, should be understood by people from all walks of life.

Third, the target language should be faithful to the original text in wording and sentence level, and at the same time maintain the style and tone of the Chinese language.

Fourth, metaphors and similes should be rendered literally, rather than be paraphrased. [1]

Among the four principles, the third one dominated the others. The first two principles describe what kind of target language should be used. The third and fourth principles show a tendency towards literal translation, viz. emphasis on form.

In the English preface to the New Testament (the NT) published in 1907, C. W. Mateer, on behalf of the translation committee, stated about the translation:

"There was considerable difference of opinion in the committee as to the degree of literalness to be aimed at. The result is a translation that must be regarded as distinctly literal and faithful to the original. As a necessary consequence, smoothness of style has been more or less sacrificed." [1]

This statement also shows that the translation of the CUV, the NT in particular, is basically literal translation.

\section{B. The Principles in the Translation of the TCV}

The guiding principles of the TCV set by a group of Bible translating experts led by Eugene A. Nida include almost every aspect of translation work

\section{1) Target Language:}

a) Functional equivalence is above formal equivalence.

b) The coherence of meaning is above that of words and sentences.

c) The spoken language is above the written language.

d) The language of people of secondary school level (people of 18 to 25 years old) is preferred.

e) The widely-used vernacular is above regional or classical language.

f) The translation must be understandable to both Christians and non-Christians.

2) Style:

a) Try to reflect different styles of Biblical language according to the functional equivalence principle. 
b) The translator is free to change the form of the ST in order to express its meaning faithfully.

\section{3) Idioms:}

a) Chinese idioms can be used when acceptable.

b) The idioms in the ST should not be rendered literally, unless their precise meaning is maintained.

\section{4) Readability of the Target Text:}

a) If the implication is relatively apparent, it should be made explicit.

b) Replace pronouns when their reference is ambiguous.

c) Use active voice if the initiator is not evident in the passive voice structure or maintain the passive structure but clarify the initiator.

d) To make the TT more smooth and understandable, the speaker of direct speech should be made clear, and direct and indirect speech can be exchanged.

e) Answers should be provided for rhetorical questions if there is no answer manifest or implied.

\section{5) Grammar:}

a) Separate long and complicated sentences when necessary.

b) The unit of translation is the paragraph and the content of verses can be rearranged.[2]

The NT translation uses the 3rd edition of the Today's English Version (the TEV) published in 1971 as the textual basis, and the evaluation group uses the Greek NT published by the U.B.S. to check it. The translator can also use the New English Bible, the Jerusalem Bible, the Revised Standard Version and other commentaries to the Bible recommended by the U.B.S. as references. [3]

To summarize the guiding principles of the translation of the TCV, it is "dynamic equivalence" as posed by Nida, who said about the purpose of translation: "Translation aims to enable new readers of the new language to obtain the same reaction as the original reader had from the verses." [4]

\section{COMPARATIVE ANALYSIS OF THE TwO VERSIONS}

This part conducts a comparative study of the two versions with the purpose to explore the different features in them, rather than to draw an easy conclusion as to which version is better than or preferable to the other.

\section{A. Language}

The CUV was written in Mandarin, which, in the late $19^{\text {th }}$ and early $20^{\text {th }}$ century, referred to the oral language used by the government and the officials. At that time, Mandarin was slightly different in different provinces but it was the language which most Chinese could understand. It was from Mandarin that today's standard Chinese, Putonghua, was developed. However, as the vernacular, Mandarin had not yet been well established, which makes the language in the CUV appear "half literary and half vernacular". The principles for the target language of the TCV determined that easy spoken language would be used. Some of the differences in the use of language are shown as follows.

\section{1) Outdated Wording vs Updated Wording}

Since the CUV was translated about a century ago, many words and expressions have undergone changes. For instance, the CUV frequently uses literary words like “焉” (an auxiliary word used before a question), “惟有” (means “only”), “尚且” (a concessive conjunction), “凡” (means all or anyone) and “务要” (must) which were popularly used in the early $20^{\text {th }}$ century but not today. So some wordings in the CUV appear outdated, while the TCV uses the expressions of today's Chinese. For instance, “娶亲的筵席” (wedding feast) in the CUV becomes “婚宴” in the TCV, “先生” (teacher) becomes “教师”, “遗传” (traditions of the ancestors) becomes “祖先的传统”, “化外之人” (foreigner) becomes “外国人”, etc.

\section{2) Literary Language vs Spoken Language}

As mentioned above, the CUV's target language Mandarin was not a fully developed spoken language, and still bore many characteristics of classical or traditional Chinese. This makes the language of the CUV appear literary and elegant. As far as elegance is concerned, the language of the CUV surpasses that of the TCV. However, the TCV's language is closer to today's spoken Chinese, which enables it to successfully realize its goal to reach the ordinary public.

\section{B. Treatment of Theological Terms}

As a religious text, words and concepts of religion and theology appear frequently throughout the Bible. The CUV inherited renderings of theological terms from its predecessors. For instance, the renderings of "天国” (Kingdom of heaven or the Kingdom of God), “福音” (gospel), “使徒” (apostle), “祈 䘠” (pray or prayer), “义” (righteousness), etc. are taken from Morrison's Version and the TCV also inherit most of them, like “外邦人” (gentiles), “属灵的恩赐” (spiritual gifts), “恩 典” (grace), “捆绑” (bound), and “偶像” (image, Rom 1:23). With non-Christians as the main readers in mind, certain theological terms in the TCV were rendered into easy language, for example “跟上帝有合宜的关系” (be justified) instead of “称义” and “法律” (The Law) instead of “律法”. Another important difference in the two versions is the rendering of "God". The CUV uses "Shen", while the TCV uses "Shangdi".

\section{Treatment of Metaphors}

The Bible contains numerous metaphors, which add charm to its language as well as difficulty in understanding. In the treatment of metaphors, the CUV generally maintains the original form, whereas the TCV tends to make explicit the implicit metaphors.

Two methods are used in the TCV to make the implicit metaphors explicit. One is to transform the metaphor into simile. For instance, in Matt 6:22, the CUV reads “眼睛就是 身体的灯" (The light of the body is the eye[5]), while the TCV reads “眼睛好比身体的灯” (The eyes are like a lamp for the body.[6]) The other method is to transform metaphor into 
non-metaphor. In Luk 11:20, the CUV says “神的指头” (the finger of God[5]), but the TCV renders it as “上帝的能力” (God's power[6]). The different treatments of metaphors are mainly influenced by their textual bases.

\section{Improved Renderings in the TCV}

\section{1) Treatment of Gender}

The TCV takes gender into consideration, which is also a characteristic of modern Chinese. One example is “弟兄们” (brethrens) in the CUV becomes “弟兄姊妹们” (brothers and sisters) in the TCV. Interestingly, the TEV still retains "brothers". The renderings of several women's names in the TCV are more appropriate for women, like “安娜” for Anna instead of “亚拿” in the CUV, “贝妮丝” for Bernice instead of “贝尼基”。

\section{2) Less Transliteration}

The TCV uses less transliteration than the CUV, which makes it clearer. For instance, “拉加” (Raca) and “魔利” in the CUV become “废物” (good-for-nothing) and “䖯东西” (a worthless fool) in the TCV, “玛门” (mammon) becomes “金 钱” (money) and “和撒那” (Hosanna) becomes “颂赞” (praise). This treatment is closely related with the texts in the RV and the TEV. In most cases, the TCV makes the implicit meanings of the words explicit, thus the verses become apparent to the today's reader.

However, there is a principle governing when transliteration should be used or not. With regard to the important words which concern basic doctrine or have traditional significance to believers, the TCV usually chooses to transliterate. [1] “阿们” (Amen), which is an exclamation expressing agreement with a statement, is a good example. It is used at the end of a prayer expressing the genuineness of the petition. All the new versions follow the transliteration method, as does the CUV, for it is such an important and frequently used word in Christian circle, that if it is rendered anything else, for example as “诚如所愿” or “但愿如此” (so let it be) it would be rejected by the Christian readers.

\section{3) Measurement of Weight, Height and Time}

In the treatment of measurements of weight, height and time, the CUV either translates them literally according to the $\mathrm{RV}$ or renders them according to the old system, whereas the TCV chooses to use the international standard measurement system. For instance, instead of using the old timing system “四更天” (in the four watch of the night), “已初” (the third hour), “午正和申初” (the sixth and ninth hour), “西初” (the eleventh hour), the TCV renders them as “天快亮的时候” (between three and six o'clock in the morning), “上午九点钟 左右” (at nine o'clock), “中午十二点钟和下午三点钟” (at twelve o'clock, at three o'clock) and “下午将近五点钟” (five o'clock).

\section{4) The Use of Active Voice}

In the principles of the TCV, there is one about the use of voice: Use active voice if the initiator is not evident in the passive voice structure or maintain the passive structure but clarify the initiator.

\section{Compare the CUV's}

“你们不要论断人, 免得你们被论断。因为你们怎样论 断人, 也必怎样被论断; 你们用什么量器量给人, 也必用 什么量器量给你们。” (Judge not, that ye be not judged. For with what judgment ye judge, ye shall be judged: and with what measure ye mete, it shall be measured to you again. [5])

with the TCV's

“不要评断人, 上帝就不审断你们。因为, 你们怎样评 断人, 上帝也要照样审断你们; 你们用什么量器来量, 上 帝也要用同样的量器量给你们。” (Do not judge others, so that God will not judge you, for God will judge you in the same way as you judge others, and he will apply to you the same rules you apply to others.[6]) in Matt 7:1-2.

The CUV uses the passive voice “你们被论断” while the TCV uses the active voice “上帝就不审断你们”, , and the initiator "Shangdi" is added according to the TEV text; whereas, the CUV follows the RV in using passive voice without indicating the initiator "God". By adding the initiator, the verse becomes clearer and avoids misunderstanding.

\section{E. Some Defects in the TCV}

Though as a later version, the TCV has many earlier versions as reference, it is not without defect. One obvious defect as the author sees it is that some renderings, whose original text appear the same, are not consistent in the TCV, such as the different rendersings of "Gentiles": in Matt 6:32 it is “不信的人”, in Matt 5:47 “异教徒”, and in Matt 10:5 “外邦人”; the rendering of “glory”: in Rom 8:18, it is “荣耀”, but in Rom 8:21 it becomes “光荣”; and the rendering of “feast or dinner”: Luk 14:15, 24 reads “䇥席”, while Luk 14:16 reads “宴会”. The CUV, on the other hand, uses “外邦人”, “荣耀” and “笾席” consistently.

\section{CONCLUSION}

The CUV and the TCV are two important versions in the history of Chinese Bible translation. Since the CUV was translated nearly a century ago by mainly foreign missionaries, its language appears literary and sometimes antique, though the target language was originally vernacular. However, because the development of language is quite a slow process, and because of the wide usage and the prestige of the CUV, it is still preferred by most people, especially Chinese Christians. Nevertheless, the popularity of the CUV cannot obliterate its defects, especially the antiquity of some words and expressions. People have noticed this from nearly 30 years ago, and much revision has been made. In the author's opinion, the 
revised edition still cannot reflect the habitual language use of today's reader in some places. Future revisions should include replacing outdated words and expressions, some transliterations as well as the measurements of weight, height and time, so the readers can get a better understanding of the scripture.

As the product of the teamwork of many experts after years of endeavour, the TCV is undoubtedly an accomplishment in Chinese Bible translation. Nevertheless, it is not a perfect version, as any other translation. The intention of the TCV translators was to produce a Bible version in modern easy Chinese so that Chinese non-Christians could accept it more easily. However, since the response of Christians affect that of non-Christian readers to a large extent, so for future revision or translation of the Bible, both Christian and non-Christian readers should be taken into consideration.

The majority of the Bible readers in China today are Christians, and the majority of them have only read one or two versions. In order to gain popularity among Chinese readers, translators, organizations or churches should take more action in the promotion of new Chinese Bible versions.

\section{ACKNOWLEDGMENT}

My greatest indebtedness is to my tutor and supervisor, Professor Li Shaoming of Shandong University, who is my model both in academe and life, and has exerted much time and energy in revising the thesis.

I am also deeply grateful to other professors of the English Department of Shandong University, who have taught me in my BA and MA years, and whose excellent expertise have helped me academically for the composition of the thesis.

\section{REFERENCES}

[1] Wai Boon, Chiu. 1993. Tracing Bible Translation: A History of the Translation of Five Modern Chinese Versions of the Bible [Z]. Hong Kong:China Graduate School of Theology.

[2] New Testament---Good News for Modern Man (Today's Chinese Version Revised Edition). 1995. Hong Kong : United Bible Societies

[3] Mushi Xu. 1983. The Bible and Its Translation [Z]. Hong Kong: Literature Press.

[4] Nida, Eugene A. 2003. Fascinated by Languages [M]. Amsterdam: John Benjamins B. V.

[5] Revised King James New Testament. The Bible Tool. Oxford: Oxford University $\quad$ Press, $1881 . \quad$ March 2007. <http://crosswire.org/study/parallelstudy.jsp?add= RNKJV>.

[6] The New Testament in Today's English Version. 1981. [Z]. London: United Bible Society. 